\title{
Anterior subcutaneous transposition of ulnar nerve with fascial flap and complete excision of medial intermuscular septum in cubital tunnel syndrome: A prospective patient cohort
}

\author{
Aslani Hamidreza ${ }^{\mathrm{a}, *}$, Abrishami Saeid ${ }^{\mathrm{a}}$, Dehghanfard Mohammadreza ${ }^{\mathrm{b}}$, Zaferani Zohreh $^{\mathrm{c}}$, \\ Saeidpour Mehdi ${ }^{\mathrm{c}}$ \\ a Shahid Beheshti University of Medical Sciences, Iran \\ ${ }^{\mathrm{b}}$ Bushehr University of Medical Sciences, Iran \\ c General Practitioner, No 57, Ehteshamieh Ave., Darrous, Tehran, Iran
}

\section{A R T I C L E I N F O}

\section{Article history:}

Received 3 March 2010

Received in revised form 26 April 2011

Accepted 8 May 2011

Available online 23 June 2011

\section{Keywords:}

Ulnar nerve compression syndromes

Cubital tunnel syndrome

Anterior subcutaneous transposition of

ulnar nerve

Modified Bishop rating system

Dellon criteria

Fisher's exact test

\begin{abstract}
A B S T R A C T
Objective: Regarding the frequency of cubital tunnel syndrome, varieties of treatment modalities, and ambiguity of anterior subcutaneous transposition of ulnar nerve method, we aimed to evaluate the efficacy of this procedure in patients with cubital tunnel syndrome referred to Taleghani hospital between 2006 and 2009.

Methods: This study was a case series including all referred patients with definite diagnosis of cubital tunnel syndrome, treated by anterior subcutaneous transposition. Treatment results were measured according to modified Bishop rating system, and were ranked into excellent, good, fair, and poor. Variables such as gender, age (less/more than 45 years), causation, and initial severity, determined by Dellon criteria preoperatively, were analyzed by Fisher's exact test.

Results: This study was performed on 26 eligible cases including 29 elbows, 38\% males and $62.1 \%$ females, with mean age of 44.5 years (ranging 23-72 years). In a 12 months follow-up post-operatively, $62 \%$ showed excellent, $20.7 \%$ good, and $17.3 \%$ fair, with no poor result. In a 1-12 months follow-up post-operatively, results showed improvement, and initial severity and old age were demonstrated to significantly affect treatment results $(P<0.07)$.

Conclusion: Though considered standard of care, the present study suggests that criteria for surgical techniques of ulnar nerve decompression, e.g. simple decompression vs. more extensive repair as in the present cohort, should be revised by controlled prospective studies.
\end{abstract}

(c) 2011 Elsevier B.V. All rights reserved.

\section{Introduction}

Ulnar nerve, comprised of $\mathrm{C}_{8}$ and $\mathrm{T}_{1}$ nerve roots, is the final branch of the medial cord of brachial plexus. This nerve lies in the upper segment of arm, posteromedial to the brachial artery, posterior to the medial intermuscular septum, and anterior to the internal head of triceps. Passing posterior to the medial epicondyle, ulnar nerve enters the cubital tunnel. Individual position of ulnar nerve in the cubital tunnel and increased tension and traction during elbow flexion make the ulnar nerve prone to compressive neuropathy [1]. Chronic neuritis of elbow was first described by Buzzard in 1992. In 1930-1940, Learmonth described ulnar nerve compression in the elbow, and subsequently introduced methods

\footnotetext{
* Corresponding author at: Department of Orthopedics, Taleghani Hospital, Shahid Beheshti University of Medical Sciences, Tehran, Iran. Tel.: +98 9121133968.

E-mail address: hraslani@yahoo.com (A. Hamidreza).
}

for decompression and transposition of compressed nerve [1]. The term "Cubital Tunnel Syndrome" was first introduced by Feindel and Startford in 1958 [2]. This syndrome is the most common compression neuropathy after carpal tunnel syndrome $[1,2]$. This syndrome presents with tingling, numbness (fourth and fifth fingers), and weakness in the hands, and inability to perform fine movements. Although clinical diagnosis has remained golden standard, electrodiagnostic studies may be utilized to confirm the diagnosis [1,3]. Treatment includes surgical and non-surgical modalities. Surgical methods are simple decompression (open or endoscopic) [4], anterior transposition (subcutaneous, intramuscular, and submuscular), and medial epicondylotomy [1,3].

Earlier reports have demonstrated that anterior subcutaneous transposition of ulnar nerve had good and excellent results ranging from $65 \%$ to $90 \%$ [2,5-11]. Although results of this procedure has been published, but results are variable between articles [2,5-11], additional studies that use reproducible preoperative and postoperative objective measures have been reported to be necessary 
Table 1

Classification of patients (Dellon criteria).

\begin{tabular}{|c|c|c|}
\hline & Sensory & Motor \\
\hline Mild & $\begin{array}{l}\text { - Paraesthesia is intermittent } \\
\text { - Vibratory perception } \\
\text { increased }\end{array}$ & $\begin{array}{l}\text { - Subjective weakness, clumsiness, } \\
\text { or loss of coordination tests } \\
\text { - Elbow flexion test, Tinel sign, or } \\
\text { both are positive }\end{array}$ \\
\hline Moderate & $\begin{array}{l}\text { - Paraesthesia is intermittent } \\
\text { - Vibratory perception } \\
\text { normal or decreased }\end{array}$ & $\begin{array}{l}\text { - Measurable weakness in pinch or } \\
\text { grip strength tests } \\
\text { - Elbow flexion test, Tinel sign, or } \\
\text { both are positive } \\
\text { - Finger crossing may be abnormal }\end{array}$ \\
\hline Severe & $\begin{array}{l}\text { - Paraesthesia is persistent } \\
\text { - Vibratory perception } \\
\text { decreased } \\
\text { - Abnormal two point } \\
\text { discrimination }\end{array}$ & $\begin{array}{l}\text { - Measurable weakness in pinch or } \\
\text { grip strength plus muscle atrophy } \\
\text { tests } \\
\text { - Elbow flexion test, Tinel sign, or } \\
\text { both are positive } \\
\text { - Finger crossing usually abnormal }\end{array}$ \\
\hline
\end{tabular}

to make a reliable decision on different surgical techniques [12]. Evaluating the results of this method will be comprehensive in condition that results are studied in long- and short-term periods. Hence, this study was designed to evaluate the anterior subcutaneous transposition of ulnar nerve, according to the condition of patients, in different periods of one month, three months, six months, and one year, attempting to evaluate effects of variables such as age, sex, etiology, and severity of disease, and to determine type and degree of complications in above periods.

\section{Materials and methods}

This study was a case series including all referred patients with the definite diagnosis of cubital tunnel syndrome, via physical examination, EMG, and NCV [1], in 2006-2009. Patients were initially treated non-surgically, and in case of unresponsiveness, surgery was performed via anterior subcutaneous transposition of ulnar nerve after six months. Patients eligible for surgery were, according to Dellon criteria, categorized into mild, moderate, and severe forms (Table 1 ).

In order to evaluate the sensory power (discrimination between two fixed points), a standard device, called Two Point Discriminator, was utilized.

After putting the patient in supine position, inflating the tourniquet, and prep and drap, upper limb was positioned on hand table, and a $15 \mathrm{~cm}$ incision was extended from 5 to $6 \mathrm{~cm}$ distal and posterior of the medial epicondyl to $10 \mathrm{~cm}$ proximal. After incision and opening the skin and subcutaneous tissue, preserving the cutaneous ante-brachial nerve, the ulnar nerve was explored in posterior of medial intermuscular septum and anterior of internal head of triceps.

Pressure points on this path were released, arcade of struther was removed, nutrient artery to the ulnar nerve was preserved as much as possible, and the intermuscular septum was completely removed. A flap of fascia of flexor and pronator muscle groups, with $1 \mathrm{in}$. length and $0.5 \mathrm{in}$. width, while base of this tongue was towards medial and its lateral border was sutured to the subcutaneous tissue was marked (Fig. 1). After releasing in above path, taking heed to and preserving the related branches to two heads of flexor carpi ulnaris, the ulnar nerve was transferred to the anterior of flexor pronator mass and placed under the fascial flap.

After finalizing the transposition and deflating the tourniquet, homeostasis was well performed, cutaneous and subcutaneous tissues were sutured, and dressing and bandage from the palmar creases to the upper arm was applied. Movement of fingers and elbows were initiated from the first day after surgery. After releasing from hospital, patients were followed up in the periods of one

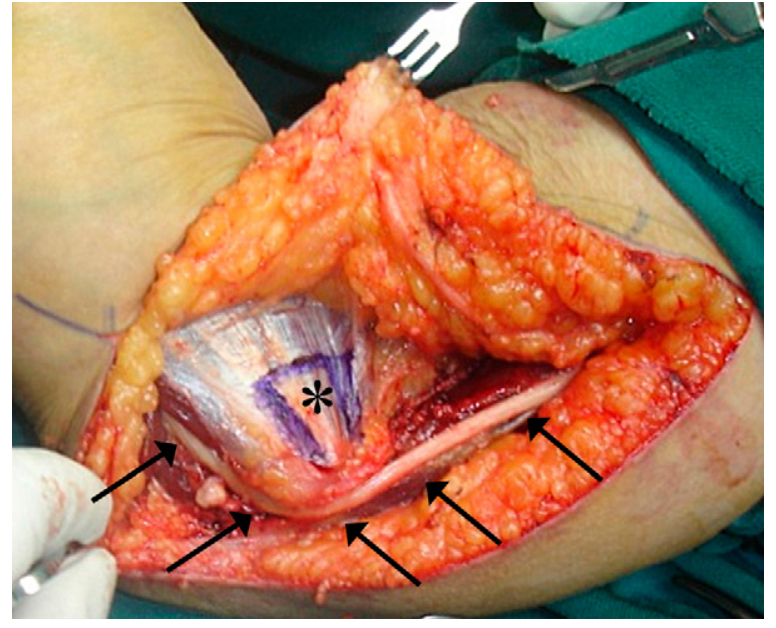

Fig. 1. Marking the fascial flap.

month, three months, six months, and one year, and data were recorded in a questionnaire.

We scored the patients as 4 or less (poor), 5 and 6 (fair), 7-9 (good), and 10-12 (excellent) according to the modified Bishop rating system (Table 2 ). Treatment trend was determined in the follow-up process and treatment results were evaluated in the last follow-up. Relation between variables such as age, sex, causation, and severity with unsuccessful results (poor and fair) and with successful results (good and excellent) were analyzed by Fisher's exact test; and odds ratio (OR), if significant, was calculated. $P$ value $<0.05$ was considered significant.

\section{Results}

26 cases including 29 elbows ( 3 were bilateral) were evaluated in our study, 16 (61.6\%) were female and 10 (38.4\%) were male, with mean age of $44.5 \pm 13.8$ years (ranging from 23 to 72 years). In the 20-40 years age group, 8 cases; $41-60$ years age group, 12 cases; and in the 61-72 years age group, 6 cases stood. Right side involvement was reported in 19 cases (65.5\%) and left side was involved in 10 cases (34.5\%). From the etiologic point of view, rheumatoid arthritis in 2 cases, cubitus valgus in 1 case, and

Table 2

Modified Bishop rating system.

\begin{tabular}{|c|c|c|}
\hline & & Points \\
\hline \multirow{3}{*}{ Satisfaction } & Satisfied & 2 \\
\hline & Satisfied with reservation & 1 \\
\hline & Dissatisfied & 0 \\
\hline \multirow{3}{*}{ Improvement } & Better & 2 \\
\hline & Unchanged & 1 \\
\hline & Worse & 0 \\
\hline \multirow{4}{*}{$\begin{array}{l}\text { Severity of residual symptoms } \\
\text { (pain, paraesthesia, } \\
\text { dysaesthesia, weakness, } \\
\text { clumsiness) }\end{array}$} & Asymptomatic & 3 \\
\hline & Mild, occasional & 2 \\
\hline & Moderate & 1 \\
\hline & Severe & 0 \\
\hline \multirow{2}{*}{ Work status } & Working or able to work at previous job & 1 \\
\hline & $\begin{array}{l}\text { Not working because of ulnar } \\
\text { neuropathy }\end{array}$ & 0 \\
\hline \multirow{2}{*}{ Leisure activity } & Unlimited & 1 \\
\hline & Limited & 0 \\
\hline \multirow{3}{*}{ Strength } & Intrinsic muscle strength normal (M5) & 2 \\
\hline & Intrinsic muscle strength reduced to M4 & 1 \\
\hline & $\begin{array}{l}\text { Intrinsic muscle strength less than or } \\
\text { equal to M3 }\end{array}$ & 0 \\
\hline \multirow{3}{*}{$\begin{array}{l}\text { Sensibility (static two-point } \\
\text { discrimination) } \\
\text { Total }\end{array}$} & Normal $(\leq 6 \mathrm{~mm})$ & 1 \\
\hline & Abnormal $(>6 \mathrm{~mm})$ & 0 \\
\hline & 12 & \\
\hline
\end{tabular}




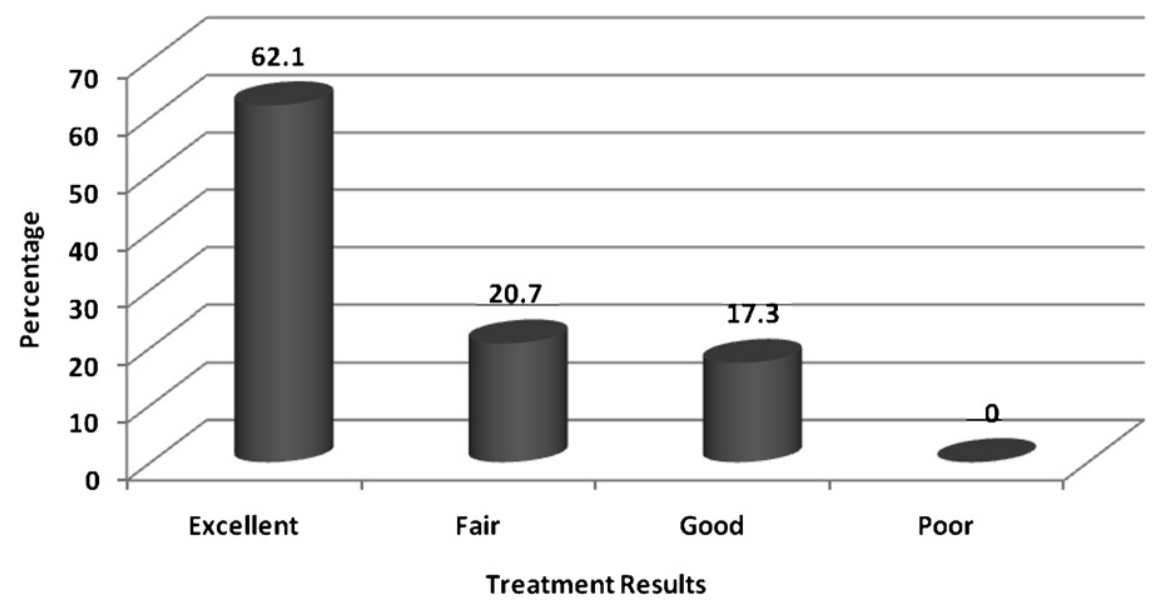

Diagram 1. Distribution of 29 elbows with cubital tunnel syndrome according to treatment results.

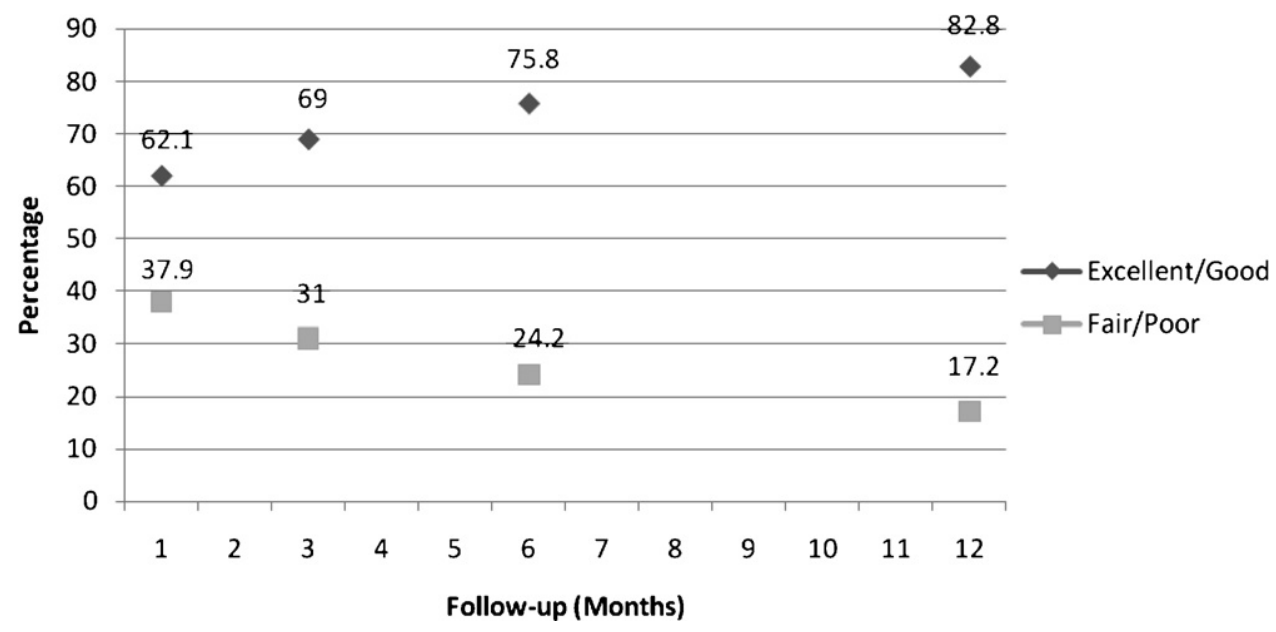

Diagram 2. Distribution of patients according to treatment results in different follow-up periods.

trauma in 8 cases were shown to be the causative factor, while 18 cases were idiopathic. Pre-operatively, 10 cases $(34.5 \%)$ were severe, 17 cases (58.6\%) were moderate, and 2 cases $(6.9 \%)$ were mild. Distribution of patients according to treatment results in the last follow-up of 12 months is shown in Diagram 1, demonstrating that there was no poor result, $17.3 \%$ had fair, $20.7 \%$ good, and $62.1 \%$ had excellent results.

Distribution of patients according to treatment results in different follow-up periods is illustrated in Diagram 2, showing that in the first month of follow-up, $37.9 \%$ of patients had poor and fair results, which declined to $31 \%, 24.2 \%$, and $17.2 \%$ in 3 months, 6 months, and 1 year follow-ups, respectively. Conversely, good and excellent results increased from $62.1 \%$ in the first follow-up (after one month) to $82.8 \%$ in the last follow up (after 12 months).
Distribution of patients according to treatment results and related factors is shown in Table 3, demonstrating that sex is not likely to be a factor influencing the treatment prognosis. In patients with poor and fair results, 4 cases (80\%) were 45 years old or more, while this was $37.5 \%$ for patients with good and excellent results $(P<0.07)$, demonstrating that patients with poor and fair results were 6.7 times more likely to be in the 45 years old or more age group than those with good and excellent results $(\mathrm{OR}=7.6)$. Etiology (known or unknown) did not affect the results, while $60 \%$ of patients with poor and fair results and $29.2 \%$ with good and excellent results had been categorized into the severe group, demonstrating that patients with poor and fair results were 3 times more likely to be in the severe group than those with good and excellent results $(\mathrm{OR}=3)$.

Table 3

Distribution of patients according to treatment results and related factors.

\begin{tabular}{|c|c|c|c|c|c|}
\hline Related Factors & Results & Excellent/good $(n=24)$ & Fair $(n=5)$ & Test result & $\mathrm{OR}^{\mathrm{a}}$ \\
\hline \multirow{2}{*}{ Sex } & Male & $10(58.33 \%)$ & $2(40 \%)$ & \multirow{2}{*}{$P<0.9$} & \multirow{2}{*}{-} \\
\hline & Female & $14(41.67 \%)$ & $3(60 \%)$ & & \\
\hline \multirow{2}{*}{ Age } & $<45 y$ & $15(62.5 \%)$ & $1(20 \%)$ & \multirow{2}{*}{$P<0.07$} & \multirow{2}{*}{6.7} \\
\hline & $\geq 45 y$ & $9(37.5 \%)$ & $4(80 \%)$ & & \\
\hline \multirow{2}{*}{ Severity } & Moderate/mild & $17(70.83 \%)$ & $2(40 \%)$ & \multirow{2}{*}{$P<0.4$} & \multirow{2}{*}{3} \\
\hline & Severe & $7(29.17 \%)$ & $3(60 \%)$ & & \\
\hline
\end{tabular}

a Odds ratio. 


\section{Discussion}

This study demonstrated that treatment of cubital tunnel syndrome with the anterior subcutaneous transposition of ulnar nerve had $62 \%$ excellent, $20.7 \%$ good, and $17.3 \%$ fair results, with no reported poor result in the 12 months follow-up.

Previous studies showed that treatment result is much more related to the disease severity than the surgery technique [6]. Our study findings are in line with the published literature [2,5-11]. In most of our patients with cubital tunnel syndrome, symptoms improved within the first year post-operatively, and returning to full activity was fast and was in about 12 days, which could be due to early initiation of ROM after operation with this surgical techniques; these results are also in consistent with previous studies [6].

Medial epicondylectomy and submuscular transposition necessitate more dissection of bone and soft tissue in comparison with subcutaneous techniques utilized in this study. Anterior intermuscular transposition necessitates less dissection in comparison with medial epicondylectomy and submuscular transposition.

It seems that submuscular transposition needs more time to return to unlimited activities. Inactivity period has been reported to be 5 weeks in these patients in previous studies, and they resumed daily routine activity after about 6 weeks [13]. Returning to severe daily activities needed at least 6 weeks, while clinical prognosis was similar in these groups [6]. Although several varieties of treatment modalities have been introduced to date, none of them take precedence.

Filippi et al. [14] showed that simple decompression of ulnar nerve is all that is needed for treatment of this syndrome; however, this method is not suggested in canal stricture due to bone spores or synovitis, in cases of scarring, and also in relapses. Assmus [15] reported good results in 93\% patients underwent simple decompression in 1984. Nevertheless, Chan et al. [16] depicted poor results in $20 \%$ of cases. A meta-analysis study suggested that there is no difference in motor nerve conduction velocities or clinical outcome scores between simple decompression and ulnar nerve transposition for the treatment of ulnar nerve compression at the elbow in patients with no prior traumatic injuries or surgical procedures involving the affected elbow [17]. Our results correspond with those reported by the others and indicate that $82.7 \%$ of patients had good and excellent results.

Present study showed no relapses or complications which, together with high good and excellent results, might be due to our novel method of surgery. In this technique, internal intermuscular septum, which is one of the most common sites of nerve compression and also influences relapse, was totally removed. Caution had been exercised not to injure nutrient artery to the ulnar nerve. In order to halter nerve anteriorly, a fascia tongue comprised of flexor and pronator groups fascia with length of $1 \mathrm{in}$. and width of $0.5 \mathrm{in}$., which was much more wider in comparison with previous studies and reference literature [1,9], while making less tension, was placed on the nerve. In this technique, internal intermuscular septum was totally removed, while only $3-5 \mathrm{~cm}$ less than what lies near the medial epicondyl was removed in previous studies and reference literature $[1,9]$. In the present study, movement of fingers, wrist, and elbow was initiated from the first day of post surgery, and hence limb was not casted. Although the majority of our sample population were house-keeper women, those working out were also had acceptable returning to full activity. In our study, 4 of 5 cases without good results were older than 45,3 of which were, according to Dellon criteria, preoperatively categorized into severe group.

\section{Conclusion}

Our study findings strongly support the concept that the anterior subcutaneous transposition of ulnar nerve is successful in patients with cubital tunnel syndrome. The present study utilizes complete excision of medial intermuscular septum plus an extended fascial flap to provide sufficient relaxation of the ulnar nerve. The weakness of the study is that the outcome assessment was not blinded as the surgeon did perform the outcome assessment. Also, the study is purely descriptive.

Though considered standard of care, the present study suggests that criteria for surgical techniques of ulnar nerve decompression, e.g. simple decompression vs. more extensive repair as in the present cohort, should be revised by controlled prospective studies.

\section{References}

[1] Green D, Hotchkiss RN, Pederson WC, Wolfe SW. Green's operative hand surgery. 5th ed. USA: Churchill Livingstone; 2005. p. 1024-43.

[2] Asamoto S, Boker DK, Jodicke A. Surgical treatment for ulnar nerve entrapment at the elbow. Neurol Med Chir (Tokyo) 2005;45:240-4 [discussion 244-5].

[3] Canale ST, Beaty JH. Campbell's operative orthopaedics. 11th ed. USA, Philadelphia: Mosby; 2008. p. 3678-88.

[4] Bartels RH, Termeer EH, van der Wilt GJ, van Rossum LG, Meulstee J, Verhagen WI, et al. Simple decompression or anterior subcutaneous transposition for ulnar neuropathy at the elbow: a cost-minimization analysis - Part 2. Neurosurgery 2005;56:531-6 [discussion 531-6]

[5] Kleinman WB. Anterior intramuscular transposition. In: Gelberman RH, editor. Operative nerve repair and reconstruction, vol. 2. Philadelphia, USA: JB Lippincott Co; 1991. p. 1069-76.

[6] Black BT, Barron OA, Townsend PF, Glickel SZ, Eaton RG. Stabilized subcutaneous ulnar nerve transposition with immediate range of motion. Long-term follow-up. J Bone Joint Surg Am 2000;82A:1544-51.

[7] Baek GH, Kwon BC, Chung MS. Comparative study between minimal medial epicondylectomy and anterior subcutaneous transposition of the ulnar nerve for cubital tunnel syndrome. J Shoulder Elbow Surg 2006;15:609-13.

[8] Nabhan A, Ahlhelm F, Kelm J, Reith W, Schwerdtfeger K, Steudel WI. Simple decompression or subcutaneous anterior transposition of the ulnar nerve for cubital tunnel syndrome. J Hand Surg Br 2005;30:521-4.

[9] Farzan M, Mortazavi SM, Asadollahi S. Cubital tunnel syn: review of 14 anterior subcutaneous transposition of the vascularized ulnar nerve. Acta medica Iranica 2005;43:197-203.

[10] Yamamoto K, Shishido T, Masaoka T, Katori Y, Tanaka S. Postoperative clinical results in cubital tunnel syndrome. Orthopedics 2006;29:347-53.

[11] Jaddue DA, Saloo SA, Sayed-Noor AS. Subcutaneous vs submuscular ulna nerve transposition in moderate cubital tunnel syndrome. Open Orthop J 2009;3:78-82.

[12] Macadam SA, Gandhi R, Bezuhly M, Lefaivre KA. Simple decompression versus anterior subcutaneous and submuscular transposition of the ulnar nerve for cubital tunnel syndrome: a meta-analysis. J Hand Surg Am 2008;33:1314e1-12.

[13] Zemel NP, Jobe FW, Yocum LA. Submuscular transposition/ulnar nerve decompression in athletes. USA, Philadelphia: JB Lippincott; 1991. p. 1097-1105.

[14] Filippi R, Farag S, Reisch R, Grunert P, Bocher-Schwarz H. Cubital tunnel syndrome. Treatment by decompression without transposition of ulnar nerve. Minim Invasive Neurosurg 2002;45:164-8.

[15] Assmus H. Operative treatment of cubital tunnel syndrome and late ulnar paralysis by simple decompression. Report on 108 cases. Neurochirurgia (Stuttg) 1984;27:181-5.

[16] Chan RC, Paine KW, Varughese G. Ulnar neuropathy at the elbow: comparison of simple decompression and anterior transposition. Neurosurgery 1980;7:545-50.

[17] Zlowodzki M, Chan S, Bhandari M, Kalliainen L, Schubert W. Anterior transposition compared with simple decompression for treatment of cubital tunnel syndrome. A meta-analysis of randomized, controlled trials. J Bone Joint Surg Am 2007;89:2591-8. 